\title{
WHEN SHOULD LEADERS SHARE INFORMATION WITH THEIR SUBORDINATES?
}

\author{
JORDI BLANES I VIDAL \\ Nuffield College \\ Oxford University \\ Oxford OX1 1NF, United Kingdom \\ jordi.blanes-i-vidal@nuffield.ox.ac.uk \\ MARC MÖLler \\ Department of Economics \\ University Carlos III de Madrid \\ Calle Madrid 126 \\ 28903 Getafe, Spain \\ mmoller@eco.uc3m.es
}

We show that when leaders share some of their information with subordinates, decision making is subject to a motivational bias; leaders make the decisions their subordinates want to see. As this bias increases with the quality of the shared information, an improvement of an organization's information might even decrease its efficiency. As a consequence, information sharing is not always optimal. We show however that self-confidence can help the leader to overcome his motivational bias, thus making information sharing more attractive. Conversely, we find that information sharing can help to curb the autocratic tendencies of a self-confident leadership. We conclude that a policy of information sharing and the appointment of a self-confident leadership are most effective when they go hand in hand.

\section{INTRODUCTION}

How to increase motivation in organizations? Unlike economists, managers tend to pay little attention to the role of explicit contracts. Instead, they often emphasise the importance of communicating effectively the organization's strategy. In a popular management handbook, Alkhafaji (1997, p. 193) states that "no matter how brilliant the strategy may be,

We thank Marco Celentani, Leonardo Felli, Eugenio Giolito, Belen Jerez, Ian Jewitt, Clare Leaver, Gilat Levy, Ulrike Malmendier, Margaret Meyer, Sujoy Mukerji, and Marco Ottaviani and participants at various seminars and conferences for valuable suggestions. We are especially grateful to Michele Piccione and Andrea Prat for their guidance and support.

(C) 2007, The Author(s)

Journal Compilation (C) 2007 Blackwell Publishing

Journal of Economics \& Management Strategy, Volume 16, Number 2, Summer 2007, 251-283 
unless the business team understands and accepts it, performance will suffer."

In many occasions, organizations can facilitate acceptance by sharing decision-relevant information with subordinates. Consider for example a CEO who has to decide on whether to initiate a merger. Although mergers require enormous implementation efforts by the rank-and-file, these efforts are by no means assured and they are likely to depend on the workers' expectations of how well the merger will result. Typically the CEO will base his decision on two types of information; verifiable "hard" information (e.g., data, statistics, or reports of external consultants) and unverifiable "soft" information (e.g., oral communication, his instinct, gut feeling or vision). Whereas the latter cannot be communicated credibly, the former can easily be shared with the company's workforce. The disclosure of such hard information can have positive motivational effects. It is more likely that the company's workers will exert high effort when they understand and agree with the decisions of the CEO. However, information sharing can also backfire and cause significant demoralisation if it reveals facts that are in conflict with the CEO's decision. An organization's communication policy must take into account this possibility and its implications for the leadership's decision making.

The first contribution of this paper is to identify conditions under which an organization should adopt a policy of information sharing. We show that information sharing allows subordinates to adjust their effort to the organization's prospects, which has a positive effect on overall surplus. On the other hand, we find that under a policy of information sharing, leaders' decision making is subject to a motivational bias; leaders have an incentive to make the decisions their subordinates want to see. To see this, suppose that in the above example the hard information does not justify the merger, but the CEO nevertheless favors it due to his additional soft information. If the company's workforce has access to the hard information the CEO might refrain from the merger because of its negative impact on the workers' motivation. This bias in favour of decisions that the CEO can justify through hard information can lead to the inefficient use of his overall information and distort decision making. The motivational bias increases as the shared information becomes more accurate. We therefore find the surprising result that an improvement of an organization's information might actually harm its efficient functioning. As a consequence, information sharing is not always optimal.

The second contribution of this paper is to establish a link between an organization's optimal communication policy and the characteristics of its leadership. Good leadership is generally considered an important 
factor in inducing motivation among subordinates. This is aptly summarised by Lee Iacocca's famous quote that "management is nothing more than motivating other people." There is less consensus, however, as to what are the exact characteristics that make a leader effective in this regard (see, e.g., Kets de Vries, 2003). An important question in this respect concerns how self-confident a leader should be. Although some leaders, that is, Bill Clinton or Louis Gerstner, are praised for their pragmatism, others, that is, Margaret Thatcher or Jack Welch, thrive by standing by their judgments in the face of opposition.

We define self-confidence as the leader's belief about the accuracy of his soft information and show that information sharing is more effective in organizations headed by individuals with high self-confidence. The reason is that self-confidence mitigates a leader's motivational bias by increasing his incentive to follow his instinct, even when it contradicts the information available to subordinates. Suppose that in our example the merger is actually the company's right course of action but the hard information does not justify it. The CEO is less likely to ignore soft information in favor of the merger when he strongly believes in his own judgement. A sufficiently self-confident CEO might go along with the merger even in the face of opposition by his workforce. We show that this can increase the organization's surplus.

While higher self-confidence can make information sharing organizations more efficient, we also find the converse result: a policy of information sharing can help to reduce the autocratic predisposition of self-confident leaders. As Malmendier and Tate (2005) show, merger failures are often due to the CEO's overconfidence in his ability to select profitable opportunities. Our model suggests that the implementation of a policy of information sharing can help an organization to avoid valuedestroying, overconfidence-driven mergers. Granting workers access to information enables them to form an opinion about a merger's viability. Because this opinion affects their motivation in the job, the CEO can find himself effectively restrained from pursuing mergers which are unduly based on his "gut feeling." Information sharing corrects a selfconfident leader's tendency to favor soft information in the same way as self-confidence corrects a leader's tendency to favor hard information when it is shared with subordinates. We therefore conclude that in organizations, information sharing and self-confident leadership work best when they are employed together.

\subsection{RELATED Literature}

This paper is the first to explore the motivational consequences of an increased transparency of decision making. Zabojnik (2002) shares our 
attempt to understand how decision making and motivational aspects in organizations interrelate and sometimes conflict with each other. He shows that informed subordinates might be more motivated to implement their own decision rather than their superior's, even if their superior is better informed. However, Zabojnik is not concerned with the subordinates' optimal information set, which is central to our work.

We are not the first to study the influence of self-confidence on managers' effectiveness. Others have studied how managers with different degrees of self-confidence enter an industry (Camerer and Lovallo, 1999), adopt projects (Bernardo and Welch, 2001) or invest (Malmendier and Tate, 2005). In contrast, this paper analyses the impact of selfconfidence on leaders' effectiveness in taking decisions and motivating subordinates.

Two papers that share our notion of a leader's vision are Rotemberg and Saloner (1994, 2000), and Van den Steen (2005). Rotemberg and Saloner focus on innovative organizations where subordinates create ideas and the leader chooses whether to test them. They show that a leader's vision can serve as a commitment device, reinforcing subordinates' innovative incentives. Van den Steen finds that visionary leaders attract subordinates who are intrinsically motivated to implement that vision. We differ from these studies by focusing on the interactions between a leader's vision and an organization's optimal information sharing policy.

This paper also relates to the economic literature on teamwork. Whereas this literature has focused exclusively either on effort (Holmstrom, 1982; Hermalin, 1998; Gervais and Odean, 2001) or on joint decision making (Aghion and Tirole, 1997; Li, Rosen, and Suen, 2001) we consider situations which require a combination of the two (see also Landier, Sraer, and Thesmar, 2006). We share with Hermalin, 1998 the assumption that the leader is privately informed about the productivity of effort. However, whereas in Hermalin (1998) the leader signals his information through his own effort choice, in our model information is transmitted through his choice of strategic direction. Hermalin's "leading by example" is probably important in small teams where subordinates can observe their leader's effort whereas in large organizations the subordinates' knowledge is more likely to be restricted to the leader's decisions.

Finally, although based in differing settings, two other papers share our finding that agents might have an incentive to conform to the views of others. Branderburger and Polak (1996) show that managers might try to conform with the opinion in the stock market in order to appear well informed. Prendergast (1993) finds that due to subjective performance evaluation workers are tempted to imitate the views of their managers. 


\subsection{OUtLine}

The plan of the paper is as follows. Section 2 introduces a simple model of leadership and explains our notion of information sharing. In Section 3 we consider efficiency under a policy of information sharing and discuss the optimality of such a policy from the viewpoint of a social planner. Section 4 introduces the notion of a leader's self-confidence and shows that the implementation of a policy of information sharing and the appointment of a self-confident leadership should go hand in hand. In Section 5 we consider the optimal organizational design from the viewpoint of an owner. Section 6 concludes. All proofs are contained in the Appendix.

\section{THE BASIC FRAMEWORK}

We analyze an organization consisting of two risk neutral agents; a leader and a subordinate. The leader is in charge of making a decision and the subordinate exerts effort to implement it. More specifically, the leader chooses a project $x \in\{A, B\}$ among two mutually exclusive projects and the subordinate exerts effort, $e \in[0, \bar{e}]$. Projects are heterogeneous in their productivity, and the identity of the most productive project, $y \in\{A, B\}$, is initially unknown.

Revenue is a function of the subordinate's effort as well as the quality of the leader's decision which is described by a dummy variable $\delta_{x y}$ equaling, 1 if $x=y$ and 0 otherwise. We assume that revenue $R\left(e, \delta_{x y}\right)$ is increasing and concave in $e$ with $R\left(0, \delta_{x y}\right)=0$. The assumption that drives our main results is that effort and decision making are complements in the sense of monotone comparative statics (see Milgrom and Shannon, 1994). In particular we assume that $R\left(e, \delta_{x y}\right)$ has strictly increasing differences in $\left(e, \delta_{x y}\right)$, that is, for all $e^{\prime}>e$ it holds that $R\left(e^{\prime}, 1\right)-R(e, 1)>R\left(e^{\prime}, 0\right)-R(e, 0)$. The subordinate's cost of exerting effort, $C(e)$, is increasing and strictly convex, with $C(0)=0$.

We assume that the subordinate receives a fixed share $\alpha \in(0,1)$ of the project's revenue while the leader receives a share $1-\alpha$. Hence the leader's payoff is $\Pi_{l}=(1-\alpha) R\left(e, \delta_{x y}\right)$ and the subordinate gets $\Pi_{s}=\alpha R\left(e, \delta_{x y}\right)-C(e)$. Total surplus is given by $S=R\left(e, \delta_{x y}\right)-C(e)$. Note that in most of this paper we abstract from explicit contracting issues. ${ }^{1}$ Our focus on linear contracts is particularly suitable for organizations in which individual goals coincide, that is, partnerships, political parties, or NGOs. It is without loss of generality if one interprets $R\left(e, \delta_{x y}\right)$ as a probability of the project's success in which case the most general

1. In Section 5 we explicitly consider the optimal incentive contracts from the viewpoint of an owner who hires the leader and the subordinate. 
contracts consist of a share of the payoff following success. ${ }^{2}$ Our results extend to more general incentive contracts as long as the leader's and the subordinate's payoffs both depend positively on revenue. Furthermore, our results are independent of $\alpha$ and therefore remain valid for $\alpha \rightarrow 1$ in which case the above contract approximates the full incentives contract.

Information. Ex ante both projects are equally likely to be the most productive. ${ }^{3}$ The leader's information consists of two informative signals about $y$. One of them, $s_{p} \in\{A, B\}$ is verifiable and has precision $p \in\left(\frac{1}{2}, 1\right)$. In addition, there exists an unverifiable signal $s_{q} \in\{A, B\}$ with precision $q \in\left(\frac{1}{2}, 1\right)$, which is the private information of the leader. Intuitively, $s_{p}$ represents "hard" evidence that can be verified by third parties, while $s_{q}$ represents valuable but "soft" insider information which the leader obtains from being in a leadership position (i.e., his vision, instinct, or gut feeling).

The focus of this paper is the desirability of a policy of information sharing. We say that the organization follows a policy of information sharing if the hard evidence $s_{p}$ is observed both by the leader and the subordinate. Under no information sharing the hard evidence is observed only by the leader and he is not allowed to share it with the subordinate. ${ }^{4}$

We do not regard the assumption that a leader uses both hard and soft information to reach a decision as controversial. Managers do not decide in a vacuum, but instead make extensive use of hard evidence like facts, statistics, and external reports. This type of evidence can be easily shared with subordinates. It is well known, however, that an important part of the information gathered by decisionmakers is based on their own judgment as well as on verbal, and even nonverbal, communication with people inside or outside the organization. $^{5}$

Timing. The timing of events is as follows. (1) Nature determines the identity of the most productive project, $y$, and the values of the signals, $s_{p}$ and $s_{q}$. (2) The leader chooses a project $x$. (3) The subordinate picks an effort level $e$ and finally the project's revenue is shared.

2. We thank an anonymous referee for this observation.

3. This assumption greatly simplifies our exposition but is not crucial to our results.

4. We have in mind situations, which constrain some hard information to the organization's leadership, that is, confidentiality arrangements which the leader cannot circumvent.

5. Yukl (2005) summarizes research on this issue by stating that leaders use informal conversations, including gossip and rumours, to form a mental picture of the issues at stake. 


\section{THE EFFICIENCY OF INFORMATION SHARING}

In this section we consider the organization from the viewpoint of a social planner. This viewpoint is particularly suitable for political parties or NGOs. When thinking of the organization as a firm consisting of a manager and a worker one might argue that it would be more appropriate to take the viewpoint of the firm's owner. In Section 5 we will see that both viewpoints are closely related so that our results not only have normative but also positive implications.

We derive two main results. First, we show that under a policy of information sharing, an improvement of the organization's information does not necessarily translate into higher surplus. Second, we find that information sharing is not always optimal and derive the conditions under which the access to hard information should be restricted to the organization's leadership.

Consider the subordinate's incentives to exert effort in period (3). On the basis of his information the subordinate forms a belief $b$ about the probability that the leader has picked the most productive project, $x=y$. Under a policy of information sharing, this belief can take two different values, depending on whether the leader's project choice, $x$, coincides with the hard evidence, $s_{p}$, or not. In the absence of information sharing the subordinate cannot make such a distinction. The subordinate's expected payoff is

$$
E\left[\Pi_{s}\right](e, b)=\alpha(b R(e, 1)+(1-b) R(e, 0))-C(e) .
$$

The subordinate chooses effort to maximize his expected payoff, given his belief $b$. The complementarity of effort and decision making implies that the subordinate's optimal effort choice, $e(b)=$ $\arg \max _{e \in[0, \bar{e}]} E\left[\Pi_{s}\right](e, b)$, is an increasing function of his belief, $b$. In the remainder of the paper we assume that $e(b)$ is strictly increasing which holds for example when revenue and costs are twice continuously differentiable.

Next, consider the leader's project choice in period (2). In the absence of information sharing the leader's optimal project choice is straightforward. He follows the most accurate of his two private signals, $s_{p}$ and $s_{q}$, thereby maximizing the project's expected productivity. The subordinate lacks information to judge the leader's decision so his effort choice, $e(\max (p, q))$, is independent of the project chosen.

In contrast, under a policy of information sharing the leader has to take into account the "motivational consequences" of his project choice as the subordinate is able to compare the leader's project choice with the hard evidence. In particular (as we will show) the subordinate is more motivated to exert effort when the leader's project choice coincides 
with the hard evidence. Under information sharing the leader therefore has an extra incentive to follow the hard evidence rather than his soft information. The following lemma characterizes the Perfect Bayesian equilibria under a policy of information sharing.

LeMmA 1: Under a policy of information sharing there exist $p_{0}$ and $p_{1}$ such that $\frac{1}{2}<p_{0}<p_{1}<q$ and the following holds:

- If $p \leq p_{0}$, there exists a unique equilibrium. The leader chooses $x=s_{q}$. The subordinate exerts effort $e\left(b_{=}^{*}\right)$ if $x=s_{p}$ and $e\left(b_{\neq}^{*}\right)$ if $x \neq s_{p}$ where $b_{\neq}^{*}=\frac{(1-p) q}{(1-p) q+(1-q) p}$ and $b_{=}^{*}=\frac{p q}{p q+(1-p)(1-q)}$.

- If $p \in\left(p_{0}, p_{1}\right)$, there exists a unique equilibrium that survives the Intuitive Criterion. The leader chooses $x=s_{p}$ with probability 1 if $s_{q}=s_{p}$ and with probability $h(p) \in(0,1)$ if $s_{q} \neq s_{p}$. The subordinate exerts effort $e\left(b_{=}^{h}\right) \in$ $\left(e(p), e\left(b_{=}^{*}\right)\right)$ if $x=s_{p}$ and $e\left(b_{\neq}^{*}\right)$ if $x \neq s_{p} . h(p)$ is continuous and strictly increasing with $p$.

- If $p \geq p_{1}$ then in every equilibrium the leader chooses $x=s_{p}$ and the subordinate exerts effort $e(p)$.

The subordinate's equilibrium effort is highest when the leader's project choice coincides with the hard evidence.

Intuitively Lemma 1 states that the leader uses the hard information when it is very precise with respect to the soft information and the soft information when the opposite is true. For intermediate values the leader uses a (random) combination of the two. The important point to note is that for values of $p$ between $p_{0}$ and $q$ the probability that the leader follows the hard evidence even when it contradicts his (more accurate) soft information is both strictly positive and increasing in $p$. In this range we regard the leader as exercising "pragmatism." He prefers to ignore his "gut feeling" in order to motivate the subordinate even if his soft information is actually more accurate than the hard evidence.

Note also that the leader cannot credibly transmit his private information with the help of a cheap talk message. The reason is that the leader's incentive to claim that his soft information coincides with his decision would render such a message uninformative.

We can relate Lemma 1 to the work of Prendergast (1993), who shows that, due to subjective performance evaluation, subordinates have an incentive to imitate the views of their superiors. Lemma 1 shows that superiors have a similar incentive but for different reasons. By making decisions based on their subordinates' views, managers can increase motivation and thus improve the implementation of their decisions. 
How does total surplus vary with the hard information's precision? As $p$ increases, the leader's decisions are based on more accurate information about the projects' productivity. One might therefore expect total surplus to be monotonically increasing in $p$. In the absence of information sharing this is indeed the case. However, under a policy of information sharing total surplus is not monotonically increasing in $p$. To understand why, consider Figure 1 which depicts an example of our

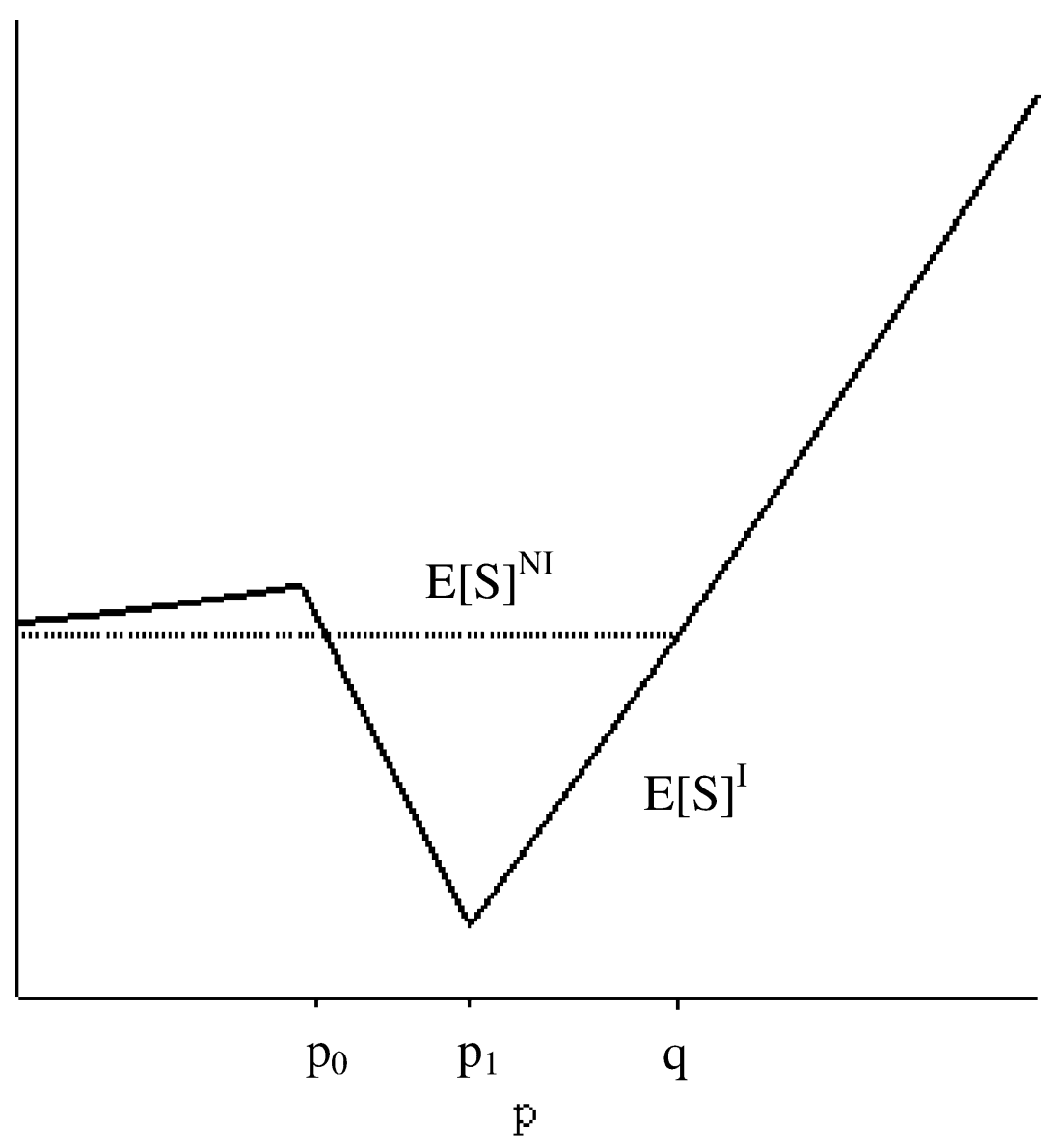

FIGURE 1. EXPECTED TOTAL SURPLUS UNDER A POLICY OF INFORMATION SHARING, E[S] $]^{I}$ AND IN THE ABSENCE OF SUCH A POLICY, E[S] $]^{N I}$, AS A FUNCTION OF THE PUBLIC SIGNAL'S PRECISION. THE EXAMPLE ASSUMES THAT $R\left(e, \delta_{x y}\right)=e \delta_{x y}, C(e)=\frac{1}{2} e^{2}$ AND $q=0.66$. THE THRESHOLDS $p_{0}$ AND $p_{1}$ TAKE THE VALUES 0.6 AND 0.625, RESPECTIVELY 
model with $R\left(e, \delta_{x y}\right)=e \delta_{x y}$ and $C(e)=\frac{1}{2} e^{2}$. Note that expected surplus under information sharing, $E[S]^{I}(p)$, decreases with the precision of the hard information for all $p \in\left(p_{0}, p_{1}\right)$. In this range, an increase in $p$ has two effects. It improves the quality of the organization's information, which is a good thing. But it also decreases the quality of decision making by increasing the probability that the leader follows the (less accurate) hard evidence in order to increase motivation. In our example this second effect is strong enough to make total surplus decrease in $p$.

Proposition 1 shows that the intuition gained from Figure 1 holds in general. As $p$ increases, the organization could potentially take better decisions and adjust effort better to the project's productivity. However, an increase in $p$ strengthens the leader's tendency to ignore his vision and improve motivation. This motivational bias is strong enough to reduce surplus.

Proposition 1: Under a policy of information sharing expected total surplus is a non-monotone function of the shared information's precision. $E[S]^{I}(p)$ is monotone increasing for all $p \in\left(\frac{1}{2}, p_{0}\right) \cup\left(p_{1}, 1\right)$ but $E[S]^{I}\left(p_{1}\right)<E[S]^{I}\left(p_{0}\right)$.

Proposition 1 highlights the hidden costs of information. It is generally acknowledged that improving an organization's information often has direct costs. Evidence has to be gathered and processed, external experts have to be hired, the communication between different organizational units has to be improved. Proposition 1 identifies an additional cost, which arises endogenously because the quality of decision making depends nonmonotonically on the hard evidence available to the organization's leadership. Because this motivational bias is present only when information is observed both by decision makers and subordinates, an immediate question arises. Should access to information be restricted to decision makers?

The benefits of sharing information are clear. As is often claimed, subordinates are more motivated to implement their superiors' decisions when they understand their logic. In our model this is due to the fact that the disclosure of information allows subordinates to adjust their effort to the project's prospects. Information sharing enables subordinates to work hard when the productivity of effort is likely to be high and save the costs of effort when it is likely to have little impact. On the other hand, we have shown above that information sharing can undermine the efficiency of decision making. In its absence, however, the leader is free from any motivational bias and always chooses the project with the highest expected productivity.

Whether information sharing is desirable or not depends on the relative size of these two effects. Our next result shows that it is the 
access to information of intermediate precision that should be restricted to the organization's leadership.

Proposition 2: There exist $p_{I}$ and $p^{I}$ with $p_{0}<p_{I} \leq p^{I}<p_{1}$ such that information sharing is optimal for efficiency for all $p \in\left(\frac{1}{2}, p_{I}\right] \cup[q, 1)$ but detrimental for all $p \in\left(p^{I}, q\right)$.

When hard evidence is very precise or very imprecise, its disclosure allows the subordinate to adjust his effort efficiently without distorting decision making. A policy of information sharing is therefore worth pursuing. However, for intermediate values of $p$, the sharing of information reduces the organization's surplus. To gain intuition, consider the range $p \in\left[p_{1}, q\right)$ in Figure 1. In this range the leader implements his (more accurate) vision in the absence of information sharing but follows the hard evidence when such evidence is observed by the subordinate. In the absence of information sharing the subordinate learns the leader's soft information from the leader's project choice. In contrast, under information sharing his information is restricted to the observation of the (less accurate) hard evidence as the leader's behaviour does not convey any additional information. Sharing information therefore distorts decision making and decreases the accuracy of the subordinate's information thereby unequivocally reducing surplus.

\subsection{BENCHMARKS}

We close this section with a discussion about the sources of inefficiency of our model. Note that there are two sources of inefficiency. First, the subordinate only receives a share $\alpha$ of the project's revenue but pays the entire cost of effort. As a consequence, the subordinate's effort choice tends to be inefficiently low. This source of inefficiency has been thoroughly studied by an extensive literature in incentive theory and is not the focus of our attention. ${ }^{6}$ Indeed in our model this inefficiency can be made arbitrarily small by choosing $\alpha$ close to one.

The second source of inefficiency stems from the informational asymmetry between leader and subordinate. Because the subordinate does not share the leader's soft information, he is not always able to adjust his effort to the project's true expected productivity. Furthermore, the leader benefits from higher effort but fails to internalize its cost, which renders him unable to credibly communicate his soft information to the subordinate. As we have seen above, this can lead to inefficient decision making; in some occasions the soft information is of higher

6. Laffont and Martimort (2001) trace back to Hume (1740) the first explicit description of the free-rider problem. See their Chapter 1 for an outline of the evolution of economic thought in this matter. 
quality than the hard information but is nevertheless ignored by the decision maker.

In order to focus on the second source of inefficiency we choose as a first best benchmark the case of symmetric information in which both leader and subordinate observe both signals. In this benchmark, the equilibrium decision rule is identical to the one in the absence of information sharing; the leader follows the soft information if and only if it is more accurate than the hard evidence. In the first best benchmark the subordinate is also able to use all the existing information to adjust his effort optimally.

When information is asymmetric, only the leader observes $s_{q}$. What is the decision rule that a social planner would like the leader to implement in the presence of this informational asymmetry? The following lemma shows that this second best decision differs from the first best.

Lemмa 2: A social planner would like the leader to follow the hard evidence if and only if $p>p^{S B}$ where $p^{S B}>q$.

The second best decision rule does not coincide with the first best when $p \in\left(q, p^{S B}\right)$. The reason is that when the hard evidence is more accurate than the soft information, the social planner faces a trade-off. On one hand, the implementation of $s_{q}$ transmits the leader's soft information to the subordinate, which allows him to adjust his effort to the team's prospects. On the other hand, the implementation of $s_{p}$ maximizes the project's expected productivity. If the hard information is less accurate than the soft information this trade-off is absent and choosing $s_{q}$ is optimal. An increase in $p$ decreases the importance of transmitting $s_{q}$ to the subordinate while increasing the likelihood that $s_{p}$ is the most productive project. When the hard evidence is extremely accurate, the subordinate has no use for additional information and the social planner would like the leader to implement $s_{p}$.

Figure 2 depicts the first and second best values of total surplus arising from the decision rules discussed above. In an information sharing organization, total surplus coincides with the first best level only when the hard information's precision is sufficiently low, that is, $p \leq p_{0}$. In this range motivational concerns are too weak for the leader to ignore his vision and he implements the first best decision rule.

When $p \in\left(p_{0}, p^{S B}\right)$, however, the leader follows the hard evidence even though second best decision making requires the exclusive use (and thus transmission) of his soft information. In this range total surplus is strictly below its second best level. For $p \in\left(p_{0}, q\right)$ this inefficiency is caused by the leader's motivational bias whereas for $p \in\left(q, p^{S B}\right)$ it is due to the fact that the leader ignores the effort-cost reduction implied by the subordinate's gain in information. 


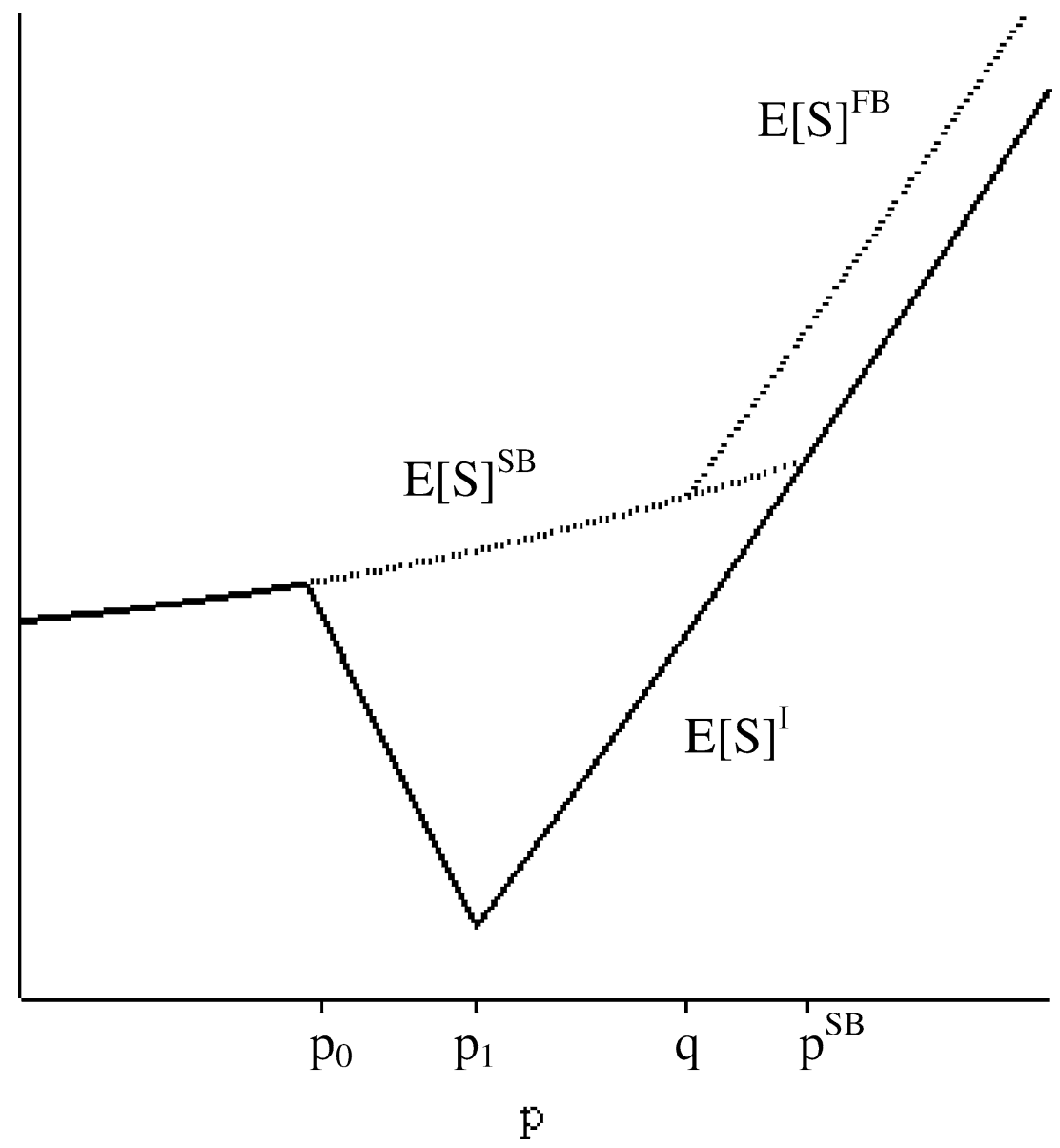

FIGURE 2. EXPECTED TOTAL SURPLUS UNDER A POLICY OF INFORMATION SHARING, E[S] ${ }^{I}$, AS A FUNCTION OF THE PUBLIC SIGNAL'S PRECISION IN COMPARISON WITH ITS FIRST AND SECOND BEST VALUES, E[S] $]^{F B}$ AND E[S] $]^{S B}$. THE EXAMPLE ASSUMES THAT $R\left(e, \delta_{x y}\right)=e \delta_{x y}, C(e)=\frac{1}{2} e^{2}$, AND $q=0.66$. THE THRESHOLDS $p_{0}, p_{1}$, AND $p^{S B}$ TAKE THE VALUES 0.6, 0.625, AND 0.68, RESPECTIVELY

Lastly, when the hard evidence is sufficiently accurate, that is, $p \geq$ $p^{S B}$, the leader's choice coincides with the one preferred by a social planner.

\section{INFORMATION SHARING AND LEADERSHIP STYLE}

Studies on leadership have long emphasised that organizations should be headed by highly self-confident individuals (see Northouse, 2004). 
However, the perils of excessive self-confidence have also merited attention (see Yukl, 2005; Malmendier and Tate, 2005). Our model allows us to study the impact of a leader's self-confidence on the decision making process and subordinates' motivation in organizations.

In particular, we show that organizations which routinely share information with subordinates can benefit from appointing a selfconfident leader. The reason is that holding a strong belief in his vision can help a decision maker to overcome the motivational bias identified in the previous section. Conversely, we also find that when an organization is headed by a highly self-confident leader, a policy of information sharing can help to curb his autocratic decision making tendencies. We end this section with the conclusion that a policy of information sharing and the appointment of a self-confident leader should go hand in hand.

\subsection{DEFINING SELF-CONFIDENCE}

We define self-confidence as optimism about the accuracy of one's knowledge. In particular, we allow for the possibility that the leader (incorrectly) believes that the precision of his soft information is $\bar{q}$ while the true precision is $q$. A larger $\bar{q}$ is associated with higher selfconfidence. The leader is considered to be realistic when $\bar{q}=q$ and overconfident when $\bar{q}>q$.

This modeling strategy is consistent with an extensive psychological literature showing that individuals tend to be overoptimistic about their own ability, and in particular about the success of their predictions (see, e.g., Fischhoff, Slovic, and Lichtenstein, 1977; Alpert and Raiffa, 1982).

Note also that we are not the first to introduce overconfidence into a standard economic framework. Economic settings with overconfident agents have been analysed, among other fields, in finance (Kyle and Wang, 1997), law (Bar-Gill, 2002), entrepreneurship (Bernardo and Welch, 2001) and production teams (Gervais and Goldstein, 2005). The particular notion of overconfidence defined above has been widely used in behavioral finance (see, e.g., for instance De Long et al., 1990; Kyle and Wang, 1997; Gervais and Odean, 2001). The empirical relevance of the overconfidence assumption in economic settings has been demonstrated, among others, by Camerer and Lovallo (1999), Barber and Odean (2001), and Malmedier and Tate (2005). Van den Steen (2004) and Zabojnik (2004) provide explanations for why overconfidence might arise even when agents are perfectly rational.

We assume that the leader's level of self-confidence is common knowledge. In particular, we assume that the leader knows that the 
subordinate believes that his soft information's precision is $q$, while the subordinate knows that the leader believes that the signal's precision is $\bar{q}$. Several points are worth mentioning here. First, common knowledge about the leader's self-confidence is the most conservative assumption in our framework. Instead, one could assume that the leader does not only consider his own information to be very precise, but also believes (rightly or wrongly) that the subordinate shares his enthusiasm. These and other alternative assumptions would only serve to reinforce the results in this section. Second note that in contrast to Aumann (1976) the leader and the subordinate are able to agree to disagree when they do not share a common prior about the quality of the leader's information. ${ }^{7}$ The above assumption is therefore completely compatible with the paradigm of Bayesian rational agents. ${ }^{8}$ Lastly, the assumption of common knowledge is supported by an extensive literature in psychology, documenting that a subject's degree of self-confidence can be predicted using some of his observable characteristics. ${ }^{9}$

In the following section we will again be concerned with the calculation of total surplus. In our model agents now have differing priors about one of the parameters of the model. We therefore need to specify which criteria to use when evaluating each agents' share of total surplus. There are two possibilities (Van den Steen 2001, see also Van den Steen, 2005). The first is to evaluate each agent's share of surplus using his subjective beliefs. If the organization's information sharing policy was determined jointly by the leader and the subordinate this approach could be appropriate. The second possibility is to evaluate total surplus from the perspective of an objective outsider using the same belief for both agents. Given that we have taken the viewpoint of a social planner we therefore use the true precision $q$ when evaluating both agents' share of surplus. This allows us to evaluate surplus from an objective perspective and to understand how surplus varies with the leader's subjective belief $\bar{q}$ holding constant the true precision $q$.

\subsection{THE PROS AND CONS OF A SELF-CONFIDENT LEADERSHIP}

In this section we justify the popular call for a self-confident leadership and highlight its perils when it becomes excessive.

7. The agents share a common prior when the leader is "realistic" (i.e., $\bar{q}=q$ ) but cannot share it when the leader is "overconfident" (i.e., $\bar{q}>q$ ).

8. Van den Steen (2004) shows that common knowledge about an individual's overconfidence arises naturally in a model with fully rational agents and differing priors.

9. Lundeberg, Cox, and Puncochar (1994) find that men are more self-confident than women, and Li et al. (2001) document that Asians are more self-confident than Westerners. 
We first show that overconfidence helps to mitigate the leader's behavioral bias identified in Section 3. We have seen there, that a "realistic leader" (i.e., $\bar{q}=q$ ) has a tendency to choose the project recommended by the hard evidence in order to increase the subordinate's motivation. It is intuitive that overconfidence makes the leader overestimate the expected gain from following his personal vision rather than the hard evidence. The following lemma therefore follows immediately.

Lemma 3: Self-confidence lowers the leader's tendency to favor hard evidence over soft information. $p_{0}$ and $p_{1}$ are strictly increasing in $\bar{q}$ whereas $h(p)$ is strictly decreasing in $\bar{q}$ for all $p \in\left(p_{0}, p_{1}\right)$.

We have seen in Section 3.1 that when the hard evidence is relatively inaccurate, that is, when $p \leq p^{S B}$, second best decision making requires the use of the leader's soft information. According to Lemma 3 , higher self-confidence shifts the leader's decision making away from the hard evidence and towards his soft information. The implications are immediate and can be seen in Figure 3. By counterbalancing the leader's motivational bias, overconfidence shifts the focus back to the soft information, thereby increasing total surplus. For values of $p$ below $p^{S B}$, a positive relation thus arises between the leader's level of selfconfidence and total surplus under information sharing.

Proposition 3: For all $p \leq p^{S B}$ expected total surplus under a policy of information sharing increases in the leader's level of self-confidence $\bar{q}$.

Proposition 3 highlights the advantages of appointing a selfconfident leader. Self-confident leaders are endowed with a strong belief in their own judgment which prevents them from sacrificing it in favor of more "pragmatic" or "accommodating" decisions. They thrive in the face of opposition to their own judgment and may therefore take better decisions.

When overconfidence is extreme, however, it can be detrimental for efficiency. This is the case when a leader's soft information is relatively inaccurate compared to the hard evidence. In this situation, an organization is better off with a realistic leader who realizes this fact than with an overconfident leader who ignores it. In other words, when the leader's vision is likely to be wrong there is no virtue in believing in it strongly.

To see this, consider the case where the hard information is so precise that second best decision making calls for its use, that is, $p>$ $p^{S B}$. A realistic leader would implement the second best level of surplus. Because he (accurately) realizes that the hard evidence is much more precise than his private soft information, a realistic leader finds no advantage in following his vision. On the other hand, an overconfident leader 


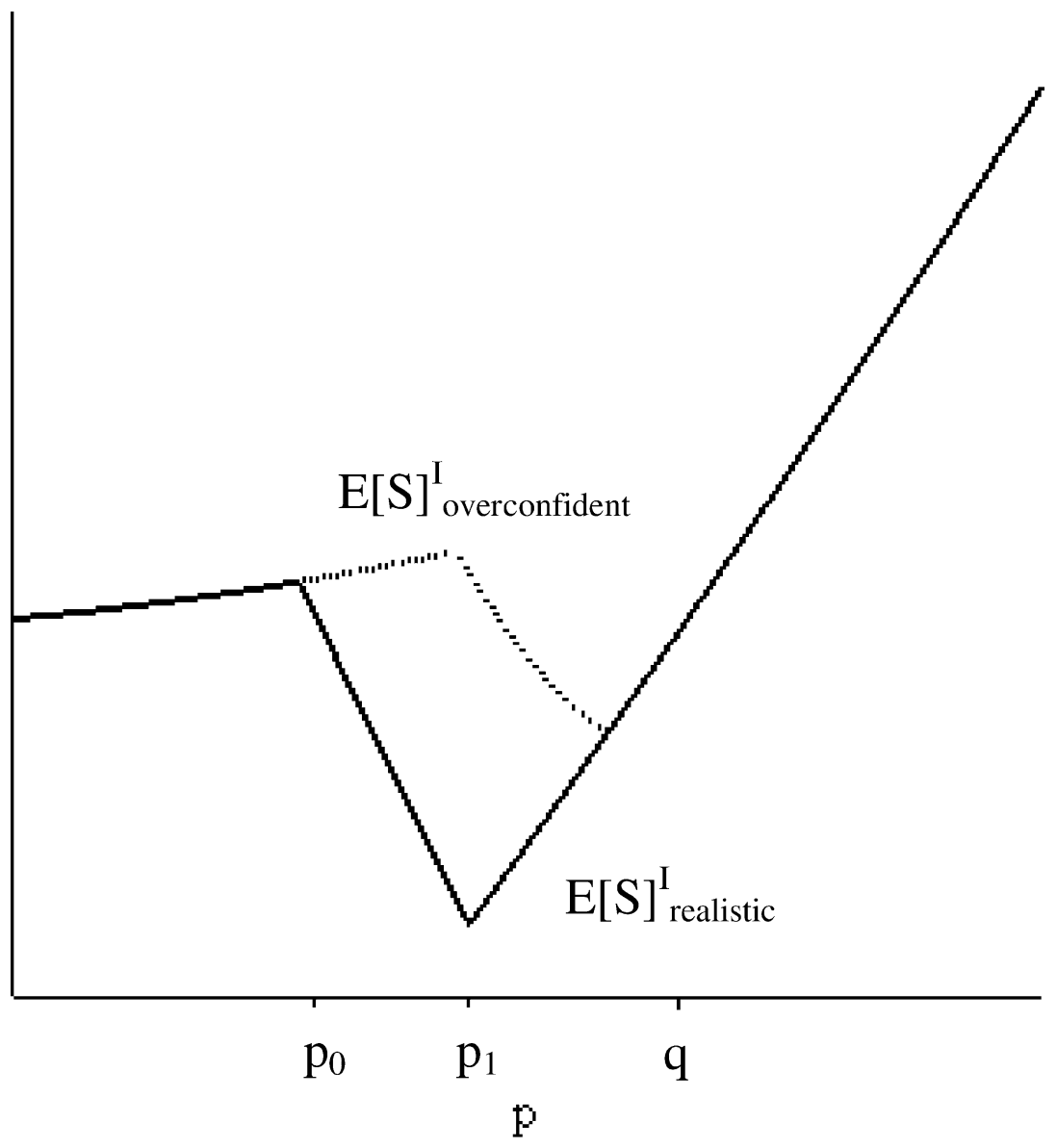

FIGURE 3. EXPECTED TOTAL SURPLUS UNDER A POLICY OF INFORMATION SHARING, E[S] ${ }^{I}$, FOR A REALISTIC LEADER $(q=0.66)$ AND AN OVERCONFIDENT LEADER ( $\bar{q}=0.7)$. THE EXAMPLE AS$\operatorname{SUMESTHATR}\left(e, \delta_{x y}\right)=e \delta_{x y} \operatorname{ANDC}(e)=\frac{1}{2} e^{2}$

overestimates the accuracy of his soft information. If he is so overconfident that $p_{0}>p^{S B}$ then for all $p \in\left(p^{S B}, p_{0}\right)$ he will base his decision exclusively on his soft information although efficiency requires the sole use of the hard evidence. A condition guaranteeing that $p_{0}>p^{S B}$ for sufficiently self-confident leaders is that

$R(e(0), 1)>R(e(1), 0)$.

Condition (2) requires revenue to be strictly greater when the leader happens to choose the most productive project and the subordinate 
believes that he has chosen the least productive one, than when the opposite is true. It implies that a leader with extreme self-confidence, $\bar{q}=$ 1 , prefers to follow his soft information regardless of the subordinate's beliefs. ${ }^{10}$ Proposition 4 formalizes this intuition.

Proposition 4: Excessive self-confidence reduces efficiency in information-sharing organizations for all $p>p^{S B}$. In particular, if (2) holds then there exists a $\bar{q}^{*}<1$ such that for all $\bar{q} \geq \bar{q}^{*}, E[S]_{\bar{q}}^{I}(p) \leq E[S]_{q}^{I}(p)$ for all $p>p^{S B}$ with strict inequality for some $p$.

\subsection{The Optimal Organizational Design}

What information sharing policy would a social planner implement and which type of leader would he appoint? In this section we argue that these two questions should not be considered separately as their answers are interrelated.

In Section 4.2 we have shown that the implementation of a policy of information sharing requires the appointment of a highly (but not excessively) self-confident leadership. Conversely, we now show, that the need for an information sharing policy increases with the leader's level of self-confidence.

For this purpose we consider the efficiency gain that results from the introduction of a policy of information sharing, $I(p, \bar{q})=E[S]_{\bar{q}}^{I}(p)-$ $E[S]_{\bar{q}}^{N I}(p)$. Information sharing is optimal when this gain is positive.

Note first that total surplus in the absence of information sharing, $E[S]_{\bar{q}}^{N I}(p)$, is weakly decreasing with the leader's level of selfconfidence. A leader with self-confidence $\bar{q}$ follows his vision if and only if he believes it to be more precise than the hard evidence. that is, iff $\bar{q} \geq p$. When $\bar{q}>p>q$ the leader follows his vision even though it is less precise than the hard evidence. Consequently, $E[S]_{\bar{q}}^{N I}(p) \leq E[S]_{q}^{N I}(p)$ for all $p$ with strict inequality for $p \in(q, \bar{q})$.

If the hard information's precision is low, that is, if $p \leq p^{S B}$, Proposition 3 therefore immediately implies that a policy of information sharing is more desirable in organizations with overconfident leaders than in organizations with realistic leaders, that is, $I(p, \bar{q}) \geq I(p, q)$.

For $p>p^{S B}$, Proposition 4 has shown that too much selfconfidence lowers expected surplus under information sharing as the leader becomes more inclined to follow his (less accurate) vision. One might be tempted to conclude from this that overconfidence makes

10. In the proof of Proposition 4 we show that Condition (2) holds when revenue and costs are twice continuously differentiable and $R^{\prime}(e, 0)-R^{\prime}(e, 1)$ and $C^{\prime \prime}(e)$ are nondecreasing which is the case for example if $R(e, i)=a_{i} e^{\frac{1}{n}}$ and $C(e)=c e^{n+1}$ with $a_{1}>a_{0}>$ $0, c>0$, and $n>1$. 
information sharing less desirable if the hard information is highly precise. This is, however, not the case. The reason is that in the absence of information sharing the leader has an even stronger incentive to follow his soft information. In organizations without information sharing the leader is free from any motivational concerns which would help to correct his overconfidence-driven decision making bias. Information sharing gives the subordinate an opportunity to compare the leader's decision with the hard evidence. Because the subordinate's motivation depends on this comparison, the leader's excessive incentive to follow his vision can be mitigated. In summary:

Proposition 5: The appointment of an overconfident leader increases the need for an information sharing policy. In particular, for all $\bar{q}>q$ it holds that $I(p, \bar{q}) \geq I(p, q)$ for all $p$ with strict inequality for some $p$.

In the absence of information sharing an overconfident leader's incentive to follow his gut feeling rather than the hard evidence is inefficiently strong. A policy of information sharing allows subordinates to form an opinion about the organization's best course of action. The leader is then forced to take into account the motivational consequences of his decision. The sharing of information thus acts as a control device. It corrects an overconfident leader's behavioral bias in the same way as self-confidence helps to overcome a realistic leader's tendency to favor hard over soft information.

We now consider a social planner's optimal organizational setup. In particular, we investigate what information policy should be implemented and which leader should be appointed in order to maximize the organization's efficiency.

For this purpose, note first that information sharing unambiguously increases surplus as long as it can be ensured that the organization's leadership will take decisions efficiently. The optimal organizational setup should therefore include a policy of information sharing and appoint a leader who is able to make efficient use of his information.

According to Lemma 2 second best decision making requires the use of the hard information if and only if $p>p^{S B}$. According to Propositions 3 and 4, the leader's optimal degree of self-confidence depends on the value of $p$. Figure 4 displays this relationship. The curve $q^{\text {min }}$ captures the minimum value of self-confidence that is required to induce a leader to choose the project according to his soft information. This minimum value is increasing in $p$. As the quality of the hard information improves, only highly self-confident leaders are able to stand by their vision. A social planner should choose a leader with a level of self-confidence higher than $q^{\min }$ when $p<p^{S B}$ and lower than 
Optimal $\overline{\mathrm{q}}$

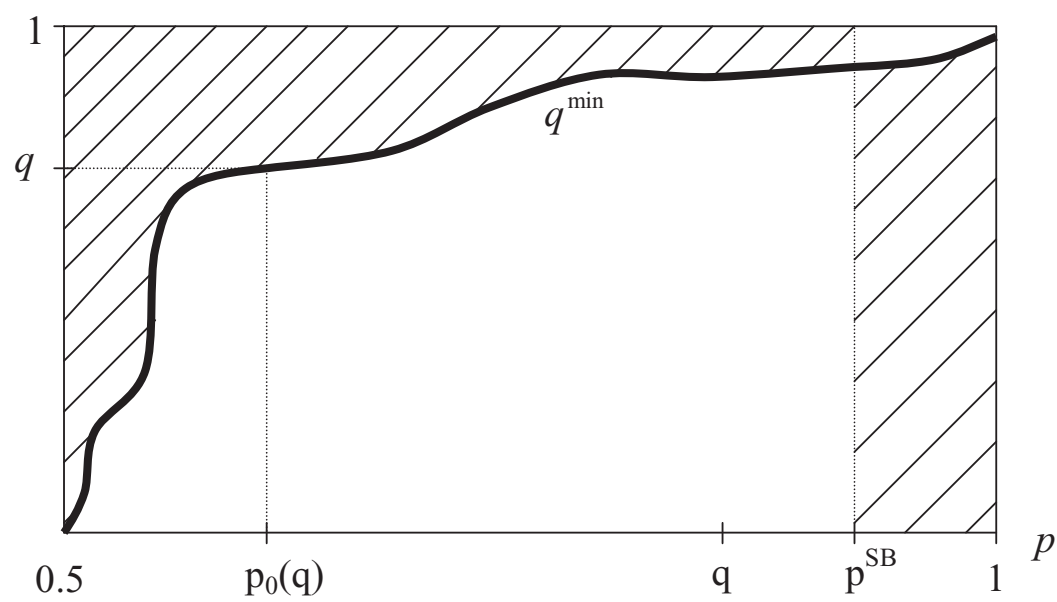

FIGURE 4. OPTIMAL ORGANIZATIONAL DESIGN. EFFICIENCY IS MAXIMIZED BY THE IMPLEMENTATION OF A POLICY OF INFORMATION SHARING AND THE APPOINTMENT OF A LEADER WITH SELF-CONFIDENCE IN THE DASHED AREA

$q^{\text {min }}$ when $p>p^{S B}$. When the hard information is not very good, it is best to avoid it, and any leader who is sufficiently self-confident about his own instincts will maximize surplus. Conversely, when the hard information is of high quality, the organization should use it and it should therefore refrain from the appointment of an excessively selfconfident leader who only cares about his vision.

\section{OWNERSHIP AND CONTRACTING}

So far our analysis has focused on the efficiency of different information sharing policies and leader types. We have thus adopted the viewpoint of a social planner studying the maximization of the organization's total surplus. We believe that this perspective is appropriate for many types of organizations, including political parties, and NGOs. However, an important interpretation of our model is the relation between a manager and a worker inside a firm. Under this interpretation it is natural to introduce a third party; the owner of the firm, who is interested in maximizing his own profits rather than total surplus and is able to set up the information sharing policy and design the agents' incentive contracts. 
To study this scenario, we consider the following extension of our basic model with a realistic leader. We assume that at time (0) the owner chooses whether the firm will follow a policy of information sharing and offers employment contracts to the leader and the subordinate. So far we have assumed that the subordinate and the leader receive a share $\alpha$ and $1-\alpha$ of the project's revenue respectively, where $\alpha \in(0,1)$ was an exogeneous parameter of the model. In contrast, we now assume that the owner offers agent $i(i \in s, l)$ an employment contract $\left(\alpha_{i}, t_{i}\right)$ that specifies a share $\alpha_{i} \in(0,1)$ of revenue to be received by agent $i$ and a (possibly negative) lump sum transfer $t_{i} \in \Re$ from the owner to agent $i$. Lastly, we normalize the leader's and the subordinate's outside options to zero.

We now consider the organization's optimal design from the viewpoint of the owner. In particular we ask under which conditions information sharing would be optimal for the owner and which employment contracts he should implement.

We first show that, independently of his choice of $\alpha_{s}$ and $\alpha_{l}$, the owner prefers to implement a policy of information sharing if and only if a social planner does so. To see this, consider the owner's payoff for given $\alpha_{l}$ and $\alpha_{s}, \Pi_{o}=\left(1-\alpha_{l}-\alpha_{s}\right) R\left(e, \delta_{x y}\right)-t_{l}-t_{s}$. This payoff is maximized by choosing transfers that make the leader and the subordinate indifferent between accepting and rejecting their contracts, that is $t_{l}=t_{l}^{*}\left(\alpha_{l}, \alpha_{s}\right) \equiv-E\left[\alpha_{l} R\right]$ and $t_{s}=t_{s}^{*}\left(\alpha_{l}, \alpha_{s}\right) \equiv-E\left[\alpha_{s} R-C\right]$. This implies that the owner can extract the entire surplus through the transfers $t_{s}^{*}$ and $t_{l}^{*}$. Substituting these optimal transfers into the owner's objective, we see that his problem simplifies into choosing the firm's information sharing policy and the shares $\alpha_{s}$ and $\alpha_{l}$ that maximize $E\left[\Pi_{o}\right]=E[R-C]$. Thus, the owner's preferences with respect to the firm's information sharing policy are identical to those of a surplus-maximizing social planner. We therefore have the following corollary.

Corollary 1: Assume that leader and subordinate are hired by an owner using linear employment contracts that specify upfront payments $t_{l}, t_{s} \in \Re$ and shares of revenue $\alpha_{l}, \alpha_{s} \in(0,1)$ for the leader and the subordinate, respectively. Then Propositions 1 and 2 remain to hold if we interchange the viewpoint of a social planner with the one of the owner.

It remains to consider the choice of $\alpha_{s}$ and $\alpha_{l}$ that maximizes the owner's payoff. Note that we have assumed that $\alpha_{l}>0 .{ }^{11}$ However, as the

11. Without this assumption the leader would always be indifferent between following his own signal or the public information so that our problem would become trivial. One might justify this assumption by the existence of a small part of revenue that is noncontractible and is captured directly by the leader, for example, a gain in future career opportunities and reputation or simply a small "warm glow" effect. 
size of $\alpha_{l}$ does not affect decision making, and hence the subordinate's effort, the owner has no incentive to offer the leader a larger share than neccessary, that is, the owner should let $\alpha_{l} \rightarrow 0$.

The situation is of course very different for the subordinate; one might expect that the owner should provide optimal incentives by letting $\alpha_{s} \rightarrow 1$ thereby making the subordinate's effort tend to its first best level. Our next result shows that this is only true in the absence of a policy of information sharing. Under information sharing, providing the subordinate with optimal incentives does not necessarily maximize the owner's revenue.

PRoposition 6: In organizations without information sharing the owner maximizes his profits by providing the subordinate with optimal incentives to exert effort, that is by letting $\alpha_{s} \rightarrow 1$. In contrast, in organizations with information sharing this need not be the case.

Providing suboptimal incentives has a direct negative effect on the subordinate's effort choice. The key to understand Proposition 6 is to realize that, under information sharing, reducing $\alpha_{s}$ can have an indirect positive impact on the quality of the leader's decision making. Note that decreasing $\alpha_{s}$ has two effects. On one hand it makes the subordinate's effort less sensitive to his belief. On the other hand it decreases the subordinate's effort for any given belief, which due to the concavity of revenue implies that revenue becomes more sensitive to effort. A decrease in $\alpha_{s}$ leads to an improvement of the leader's decision making when the first effect is sufficiently strong relative to the second. In the proof of Proposition 6 we provide an example in which this occurs. In this example the improvement in the leader's decision making more than compensates for the decrease in the subordinate's effort level thereby increasing the owner's payoff. In the presence of information sharing, providing the subordinate with suboptimal incentives can maximize the owner's payoff through its positive effect on the leader's decision making.

It is important to note that we are using a framework in which the subordinate is risk neutral, has unlimited liability, undertakes effort in only one task, and does not have private information about the cost of his effort. It is a well-known result of incentive theory that, under these circumstances, an owner cannot do better than by "selling the firm" to the subordinate. Our findings suggest however that this might not be the case when decision making and implementation are separated and the firm adopts a policy of information sharing. Providing workers with optimal incentives to exert effort can have a negative externality on the ability of managers to take the right decisions. 


\section{CONCLUSiON}

How much information should subordinates receive about an organization's strategic direction? What type of leader should be appointed? In this paper we have shown that the answers to these two questions are connected. Information sharing, although not always optimal, is more effective under self-confident leaders, who are able to take difficult decisions that might not be easily understood by partially informed subordinates. Conversely, self-confident leaders are more successful when their eagerness to follow their own instincts is curbed by a policy of information sharing.

In what industries should we therefore expect to find overconfident leaders? Our findings suggest that firms operating in uncertain environments (growth firms) where public evidence is likely to be of low quality will appoint more overconfident managers. Bill Gates and Steve Jobs, for example, are widely regarded as leaders with strong confidence in their vision. In contrast, firms that are able to base their decisions on a rich collection of hard evidence, that is, those operating in mature industries, will employ more realistic, pragmatic managers.

With respect to the information sharing policy the predictions of our model are less straightforward. Much depends on whether or not a firm is able to appoint the right type of decision maker. Firms that are able to adjust leadership to their environment, thus eliminating the scope for motivational bias, will always adopt a policy of information sharing. In contrast, firms stuck with leaders whose self-confidence is not sufficient to overcome their motivational bias might refrain from the sharing of information.

In practice it might sometimes be easier to change an organization's leadership than to make it more transparent. A large part of knowledge disclosure in organizations is determined by institutional rules and procedures. Examples are a company's divisional structure or a country's constitution. When these features are difficult to adjust in a rapidly changing environment, changes in leadership are the natural consequence.

There are occasions, however, where the opposite might occur. When an overconfident individual is entrenched in a CEO position, a company's board might find it more difficult to remove him than to compel him to routinely meet with his managers and publish relevant and timely information. As we pointed out in the introduction, the advantages of forcing him to share this information could include the prevention of overconfidence-driven, value-destroying mergers and acquisitions. 


\section{APPENDIX}

Proof of Lemma 1. To abbreviate notation let $R_{i}(e) \equiv R(e, i)$ for $i \in\{0,1\}$. Denote by $b_{=}$and $b_{\neq}$the subordinate's equilibrium beliefs conditional on observing $x=s_{p}$ and $x \neq s_{p}$, respectively. Define the function

$$
\begin{aligned}
G\left(b_{=}, b_{\neq}\right)= & \left\{R_{1}\left(e\left(b_{\neq}\right)\right)-R_{0}\left(e\left(b_{=}\right)\right)\right\} \\
& +\frac{(1-q) p}{q(1-p)}\left\{R_{0}\left(e\left(b_{\neq}\right)\right)-R_{1}\left(e\left(b_{=}\right)\right)\right\}
\end{aligned}
$$

that is proportional to the leader's expected gain from choosing $x=s_{q}$ rather than $x=s_{p}$. Let $h$ denote the leader's probability of choosing $x=$ $s_{p}$ after observing $s_{p} \neq s_{q}$. Suppose first that $h=0$. Bayesian updating implies that $b_{\neq}=\frac{(1-p) q}{(1-p) q+(1-q) p} \equiv b_{\neq}^{*}$ and $b_{=}=\frac{p q}{p q+(1-p)(1-q)} \equiv b_{=}^{*} \cdot h=$ 0 is a feasible equilibrium if and only if

$G\left(b_{=}^{*}, b_{\neq}^{*}\right) \geq 0$.

Suppose now that $h=1$. The subordinate's belief is $b_{=}=p$ if the leader follows the equilibrium. In a Perfect Bayesian Equilibrium, beliefs off the equilibrium path can be chosen arbitrarily. Here we use the Intuitive Criterion as a selection device. ${ }^{12}$ Because the leader never has an incentive to choose $x \neq s_{p}$ after observing $s_{p}=s_{q}$, the only belief that survives the Intuitive Criterion is $b_{\neq}=b_{\neq}^{*}$. Thus, $h=1$ is an equilibrium if and only if

$G\left(p, b_{\neq}^{*}\right) \leq 0$.

Finally assume that $h \in(0,1)$. Bayesian updating implies that $b_{\neq}=b_{\neq}^{*}$ and

$b_{=}=\frac{p q+h p(1-q)}{p q+(1-p)(1-q)+h(p(1-q)+q(1-p))} \equiv b_{=}^{h}$.

In equilibrium the leader has to be indifferent between $x=s_{q}$ and $x=$ $s_{p} . h \in(0,1)$ is an equilibrium if and only if

$G\left(b_{=}^{h}, b_{\neq}^{*}\right)=0$.

Note that for all $h \in[0,1], b_{=}$is increasing in $p$ whereas $b_{\neq}$is decreasing. We now show that $G\left(b_{=}, b_{\neq}\right)$is decreasing in $p$ whenever $p$ is such that $G\left(b_{=}, b_{\neq}\right)=0$. For the partial derivative we find

12. Strictly speaking, such criterion is defined for signaling games but its extension to our case is straightforward and its definition is omitted. 


$$
\begin{aligned}
\frac{\partial G}{\partial p} & =\frac{1-q}{q(1-p)^{2}}\left(R_{0}\left(e\left(b_{\neq}\right)\right)-R_{1}\left(e\left(b_{-}\right)\right)\right) \\
& =\frac{1}{p(1-p)}\left(R_{0}\left(e\left(b_{-}\right)\right)-R_{1}\left(e\left(b_{\neq}\right)\right)\right) .
\end{aligned}
$$

If $b_{=}>b_{\neq}$then $R_{0}\left(e\left(b_{\neq}\right)\right)<R_{1}\left(e\left(b_{=}\right)\right)$and if $b_{=} \leq b_{\neq}$then $R_{0}\left(e\left(b_{=}\right)\right)<$ $R_{1}\left(e\left(b_{\neq}\right)\right)$. This implies that $\frac{\partial G}{\partial p}<0$. The total derivative may not exist. However, the fact that effort is increasing in the subordinate's belief and revenue is increasing in effort implies that $G\left(b_{=}, b_{\neq}\right)$is decreasing in $p$. We start the equilibrium analysis by considering the case where $h=0$. Note that $b_{=}=b_{=}^{*}>b_{\neq}^{*}=b_{\neq}$. Condition (A2) in the limits becomes

$$
\begin{aligned}
& \lim _{p \rightarrow \frac{1}{2}} G\left(b_{=}^{*}, b_{\neq}^{*}\right)=\frac{2 q-1}{q}\left(R_{1}(e(q))-R_{0}(e(q))\right)>0 \\
& \left.\lim _{p \rightarrow q} G\left(b_{=}^{*}, b_{\neq}^{*}\right)=R_{1}\left(e\left(b_{\neq}^{*}\right)\right)-R_{1}\left(e\left(b_{=}^{*}\right)\right)+R_{0}\left(e\left(b_{\neq}^{*}\right)\right)-R_{0}\left(e\left(b_{=}^{*}\right)\right)\right)<0 .
\end{aligned}
$$

As $G\left(b_{=}^{*}, b_{\neq}^{*}\right)$ cannot cross 0 from below and as $G\left(b_{=}^{*}, b_{\neq}^{*}\right)$ is continuous in $p$, (A2) holds if and only if $p \leq p_{0}$ for some $p_{0} \in\left(\frac{1}{2}, q\right)$. Now consider the case $h=1$. Note that for (A3) to hold $b_{=}=p$ has to be strictly larger than $b_{\neq}=b_{\neq}^{*}$. In the limits we have

$$
\begin{aligned}
\lim _{p \rightarrow \frac{1}{2}} G\left(p, b_{\neq}^{*}\right)= & \frac{1-q}{q}\left(R_{0}(e(q))-R_{1}\left(e\left(\frac{1}{2}\right)\right)\right) \\
& +R_{1}(e(q))-R_{0}\left(e\left(\frac{1}{2}\right)\right)>0
\end{aligned}
$$

$\lim _{p \rightarrow q} G\left(p, b_{\neq}^{*}\right)=R_{1}\left(e\left(\frac{1}{2}\right)\right)-R_{1}(e(q))+R_{0}\left(e\left(\frac{1}{2}\right)\right)-R_{0}(e(q))<0$.

Thus a similar argument as above implies that (A3) holds if and only if $p \geq p_{1}$ for some $p_{1} \in\left(\frac{1}{2}, q\right)$. To see that $p_{0}<p_{1}$ note that $b_{=}^{*}>p$ for all $p$ which implies that $G\left(p, b_{\neq}^{*}\right)>G\left(b_{=}^{*}, b_{\neq}^{*}\right)$ for all $p$.

Finally consider condition (A5). For (A5) to hold we need that $b_{=}=b_{=}^{h}>b_{\neq}=b_{\neq}^{*}$. Note that $b_{=}^{h}$ is strictly decreasing in $h$. This implies that $G\left(b_{=}^{h}, b_{\neq}^{*}\right)$ is strictly increasing in $h$ so that any $h(p)$ that solves (A5) has to be unique. Moreover $\lim _{h \rightarrow 0} b_{=}^{h}=b_{=}^{*}$ and $\lim _{h \rightarrow 1} b_{=}^{h}=p$ imply that there exists a $h(p) \in(0,1)$ which satisfies (A5) if and only if (A2) and (A3) are both violated. Moreover, the fact that $G\left(b_{=}^{h}, b_{\neq}^{*}\right)$ is continuous and decreasing in $p$ whenever $G\left(b_{=}^{h}, b_{\neq}^{*}\right)=0$ implies that $h(p)$ has to be continuous and strictly increasing. 
Proof of Proposition 1. Define the values of expected total surplus when the project is chosen according to the soft and hard information, respectively:

$$
\begin{aligned}
E[S]^{S}(p)= & \operatorname{Pr}\left(s_{q}=s_{p}\right)\left(b_{=}^{*} R_{1}\left(e\left(b_{=}^{*}\right)\right)+\left(1-b_{=}^{*}\right) R_{0}\left(e\left(b_{=}^{*}\right)\right)-C\left(e\left(b_{=}^{*}\right)\right)\right) \\
& +\operatorname{Pr}\left(s_{q} \neq s_{p}\right)\left(b_{\neq}^{*} R_{1}\left(e\left(b_{\neq}^{*}\right)\right)+\left(1-b_{\neq}^{*}\right) R_{0}\left(e\left(b_{\neq}^{*}\right)\right)-C\left(e\left(b_{\neq}^{*}\right)\right)\right)
\end{aligned}
$$

$$
E[S]^{H}(p)=p R_{1}(e(p))+(1-p) R_{0}(e(p))-C(e(p)) .
$$

First, we show that $E[S]^{S}$ is increasing. The subordinate's expected payoff can be written as

$$
E\left[\Pi_{s}\right]^{S}=\operatorname{Pr}\left(s_{q}=s_{p}\right) E\left[\Pi_{s}\right]^{S}\left(b_{=}^{*}\right)+\operatorname{Pr}\left(s_{q} \neq s_{p}\right) E\left[\Pi_{s}\right]^{S}\left(b_{\neq}^{*}\right)
$$

where $E\left[\Pi_{s}\right]^{S}(b)=\max _{e} \alpha\left(b R_{1}(e)+(1-b) R_{0}(e)\right)-C(e)$. As the subordinate's objective is linear in $b, E\left[\Pi_{s}\right]^{S}(b)$ is convex. As $b_{=}^{*}-b_{\neq}^{*}$ is increasing in $p$ and $\operatorname{Pr}\left(s_{q}=s_{p}\right) b_{=}^{*}+\operatorname{Pr}\left(s_{q} \neq s_{p}\right) b_{\neq}^{*}=q$ is constant it follows that the subordinate's expected payoff, $E\left[\Pi_{s}\right]^{S}$, is increasing in $p$. To see that the leader's expected payoff is also increasing consider expected revenue, $E[R]^{S}$. The subordinate's maximization program can be written as

$$
E\left[\Pi_{s}\right]^{S}=\max _{\tilde{R}} \alpha \tilde{R}-\tilde{C}(\tilde{R}, p),
$$

where

$$
\tilde{C}(\tilde{R}, p)=\min _{e_{=}, e_{\neq}}\left[\operatorname{Pr}\left(s_{q}=s_{p}\right) C\left(e_{=}\right)+\operatorname{Pr}\left(s_{q} \neq s_{p}\right) C\left(e_{\neq}\right)\right]
$$

$$
\text { s.t. } \begin{aligned}
\tilde{R}= & p q R_{1}\left(e_{=}\right)+(1-p)(1-q) R_{0}\left(e_{=}\right)+(1-p) q R_{1}\left(e_{\neq}\right) \\
& +p(1-q) R_{0}\left(e_{\neq}\right)
\end{aligned}
$$

is the minimum expected cost of achieving the expected revenue $\tilde{R}$. As it is less costly for the subordinate to increase revenue when he is better informed, $-\tilde{C}$ has increasing differences in $(\tilde{R}, p)$. This implies that the subordinate's optimal choice of expected revenue $\arg \max _{\tilde{R}} \alpha \tilde{R}-$ $\tilde{C}(\tilde{R}, p)=E[R]^{S}$ is increasing in $p$.

Second, we show that $E[S]^{H}$ is increasing. For $p>p^{\prime}$ we have

$$
\begin{aligned}
E[S]^{H}(p)-E[S]^{H}\left(p^{\prime}\right)> & (1-p)\left(R_{0}(e(p))-R_{0}\left(e\left(p^{\prime}\right)\right)\right) \\
& +p\left(R_{1}(e(p))-R_{1}\left(e\left(p^{\prime}\right)\right)\right)-C(e(p))+C\left(e\left(p^{\prime}\right)\right)
\end{aligned}
$$$$
>\left(1-\frac{1}{\alpha}\right)\left(C\left(e\left(p^{\prime}\right)\right)-C(e(p))\right)>0 .
$$ 
The first inequality follows as $p>p^{\prime}$ and the second inequality uses that $e(p)=\arg \max _{e \in[0, \bar{e}]} p R_{1}(e(p))+(1-p) R_{0}(e(p))-\frac{1}{\alpha} C(e(p))$.

Finally, consider expected total surplus under information sharing, $E[S]^{I}$. According to Lemma $1, E[S]^{I}(p)=E[S]^{S}(p)$ for all $p \in$ $\left(\frac{1}{2}, p_{0}\right]$ and $E[S]^{I}(p)=E[S]^{H}(p)$ for all $p \in\left[p_{1}, 1\right)$. It follows that $E[S]^{I}(p)$ is increasing for all $p \in\left(\frac{1}{2}, p_{0}\right) \cup\left(p_{1}, 1\right)$. $E[S]^{I}(p)$ is nonmonotone as $E[S]^{I}\left(p_{0}\right)=E[S]^{S}\left(p_{0}\right)>\lim _{p \rightarrow \frac{1}{2}} E[S]^{S}(p)=E[S]^{H}(q)>$ $E[S]^{H}\left(p_{1}\right)=E[S]^{I}\left(p_{1}\right)$ where the last inequality follows from $q>p_{1}$.

Proof of Proposition 2. The continuity of $h(p)$, and the fact that $\lim _{p \rightarrow p_{0}} h(p)=0$ and $\lim _{p \rightarrow p_{1}} h(p)=1$, implies that $E[S]^{I}$ is a continuous function of $p$. Denote expected surplus in the absence of information sharing by $E[S]^{N I}(p)$. For all $p \leq q, E[S]^{N I}(p)=E[S]^{H}(q)$. As $\lim _{p \rightarrow \frac{1}{2}} E[S]^{I}(p)=E[S]^{H}(q)$ and $E[S]^{I}(p)$ is increasing in $p$ for all $p \in$ $\left(\frac{1}{2}, p_{0}\right)$ it follows that information sharing is optimal for all $p \in\left(\frac{1}{2}, p_{0}\right)$. Let $p_{I}$ and $p^{I}$ be the smallest and largest solution to $E[S]^{I}(p)=E[S]^{N I}(p)$ in $\left(p_{0}, p_{1}\right)$. $p_{I}$ and $p^{I}$ exist as $E[S]^{I}\left(p_{0}\right)>E[S]^{N I}\left(p_{0}\right)$ and $E[S]^{I}\left(p_{1}\right)=$ $E[S]^{H}\left(p_{1}\right)<E[S]^{H}(q)=E[S]^{N I}\left(p_{1}\right)$, and surplus is continuous in $p$. If $E[S]^{I}(p)$ is strictly decreasing in $\left(p_{0}, p_{1}\right)$ then $p_{I}=p^{I}$. By definition $E[S]^{I}(p)>E[S]^{N I}(p)$ for all $p \in\left(\frac{1}{2}, p_{I}\right)$ and $E[S]^{I}(p)<E[S]^{N I}(p)$ for all $p \in$ $\left(p^{I}, q\right)$. For $p \geq q$ it is immediate that $E[S]^{I}(p)=E[S]^{H}(p)=E[S]^{N I}(p)$.

Proof of Lemma 2. Consider $E[S]^{S}$ and $E[S]^{H}$ as defined in the proof of Proposition 1. Note that

$\lim _{p \rightarrow \frac{1}{2}} E[S]^{S}(p)=E[S]^{H}(q)>E[S]^{H}\left(\frac{1}{2}\right)=\lim _{p \rightarrow \frac{1}{2}} E[S]^{H}(p)$

and

$$
\begin{aligned}
\lim _{p \rightarrow 1} E[S]^{S}(p)= & q\left(R_{1}(e(1))-C(e(1))\right)+(1-q)\left(R_{0}(e(0))-C(e(0))\right) \\
& <R_{1}(e(1))-C(e(1))=\lim _{p \rightarrow 1} E[S]^{H}(1) .
\end{aligned}
$$

In the proof of Proposition 1 we have shown that $E[S]^{S}$ and $E[S]^{H}$ are both increasing in $p$. However, $E[S]^{S}$ increases less strongly than $E[S]^{H}$. When $x=s_{p}$, an increase in $p$ improves the subordinate's information and increases the project's expected productivity. The latter effect is absent when $x=s_{q}$. This implies that there exists a $p^{S B}$ such that $E[S]^{S}(p) \geq$ $E[S]^{H}(p)$ if and only if $p \leq p^{S B}$. Finally, as for $p=q$ both decision rules have identical expected productivities but $x=s_{q}$ improves the subordinate's information, it has to hold that $p^{S B}>q$. 
Proof of Lemma 3. For a leader with self-confidence $\bar{q}$ we have to substitute the function $G$ which measures the leader's gain from choosing $x=s_{q}$ rather than $x=s_{p}$ by

$$
G_{\bar{q}}\left(b_{=}, b_{\neq}\right)=\left\{R_{1}\left(e\left(b_{\neq}\right)\right)-R_{0}\left(e\left(b_{=}\right)\right)\right\}+\frac{(1-\bar{q}) p}{\bar{q}(1-p)}\left\{R_{0}\left(e\left(b_{\neq}\right)\right)-R_{1}\left(e\left(b_{=}\right)\right)\right\}
$$

in the equilibrium conditions (A2), (A3), and (A5). The fact that $G_{\bar{q}}\left(b_{=}, b_{\neq}\right)$is strictly increasing in $\bar{q}$ implies that $p_{0}$ and $p_{1}$ are strictly increasing in $\bar{q}$. Moreover, as $G_{\bar{q}}\left(b_{=}^{h}, b_{\neq}\right)$is strictly increasing in $h$ and $h(p)$ solves $G_{\bar{q}}\left(b_{=}^{h}, b_{\neq}\right)=0$ it follows that $h(p)$ is strictly decreasing in $\bar{q}$.

Proof of Proposition 3. Expected surplus is unaffected by a change in $\bar{q}$ as long as this change does not alter the leader's equilibrium behavior, that is, his probability $h$ of choosing $x=s_{p}$ after observing $s_{p} \neq s_{q} . h=$ 0 for all $p \leq p_{0}, h=1$ for all $p \geq p_{1}$ and $h=h(p)$ for all $p \in\left(p_{0}, p_{1}\right)$. According to Lemma $3, h$ is weakly decreasing in $\bar{q}$. We now show that a decrease in $h$ raises expected total surplus for all $p \leq p^{S B}$. Suppose that $\bar{q}^{\prime}>\bar{q}$ and let $h^{\prime}, h \in[0,1]$ with $h^{\prime} \leq h$ denote the associated probabilities of choosing $x=s_{p}$ after observing $s_{p} \neq s_{q}$. To abbreviate notation let $e_{\neq}^{*}=e\left(b_{\neq}^{*}\right), e_{=}^{h}=e\left(b_{=}^{h}\right)$ and $e_{=}^{h^{\prime}}=e\left(b_{=}^{h^{\prime}}\right)$. We get

$$
\begin{aligned}
E[S]_{\bar{q}}^{I}(p)= & \operatorname{Pr}\left(s_{p}=s_{q}\right)\left\{b_{=}^{*} R_{1}\left(e_{=}^{h}\right)+\left(1-b_{=}^{*}\right) R_{0}\left(e_{=}^{h}\right)-C\left(e_{=}^{h}\right)\right\} \\
& +\operatorname{Pr}\left(s_{p} \neq s_{q}\right)\left\{h\left[\left(1-b_{\neq}^{*}\right) R_{1}\left(e_{=}^{h}\right)+b_{\neq}^{*} R_{0}\left(e_{=}^{h}\right)-C\left(e_{=}^{h}\right)\right]\right. \\
& \left.\left.+(1-h)\left[b_{\neq}^{*} R_{1}\left(e_{\neq}^{*}\right)+\left(1-b_{\neq}^{*}\right) R_{0}\left(e_{\neq}^{*}\right)-C\left(e_{\neq}^{*}\right)\right)\right]\right\} \\
\leq & \operatorname{Pr}\left(s_{p}=s_{q}\right)\left\{b_{=}^{*} R_{1}\left(e_{=}^{h}\right)+\left(1-b_{=}^{*}\right) R_{0}\left(e_{=}^{h}\right)-C\left(e_{=}^{h}\right)\right\} \\
& +\operatorname{Pr}\left(s_{p} \neq s_{q}\right)\left\{h^{\prime}\left[\left(1-b_{\neq}^{*}\right) R_{1}\left(e_{=}^{h}\right)+b_{\neq}^{*} R_{0}\left(e_{=}^{h}\right)-C\left(e_{=}^{h}\right)\right]\right. \\
& \left.\left.+\left(1-h^{\prime}\right)\left[b_{\neq}^{*} R_{1}\left(e_{\neq}^{*}\right)+\left(1-b_{\neq}^{*}\right) R_{0}\left(e_{\neq}^{*}\right)-C\left(e_{\neq}^{*}\right)\right)\right]\right\} \\
\leq & E[S]_{\bar{q}^{\prime}}^{I}(p) .
\end{aligned}
$$

The first inequality is strict when $h^{\prime}<h$ and $p<p^{S B}$ as the social planner's preference for $x=s_{q}$ implies that

$$
\begin{aligned}
& b_{\neq}^{*} R_{1}\left(e_{\neq}^{*}\right)+\left(1-b_{\neq}^{*}\right) R_{0}\left(e_{\neq}^{*}\right)-C\left(e_{\neq}^{*}\right)>\left(1-b_{\neq}^{*}\right) R_{1}\left(e_{=}^{h}\right) \\
& \quad+b_{\neq}^{*} R_{0}\left(e_{=}^{h}\right)-C\left(e_{=}^{h}\right) .
\end{aligned}
$$


The second inequality follows from the fact that $e_{=}^{h^{\prime}}$ maximizes the subordinate's objective when his belief is $b_{=}^{h^{\prime}}$ and $e_{=}^{h^{\prime}}>e_{=}^{h}$ so that

$$
\begin{aligned}
b_{=}^{h^{\prime}} & R_{1}\left(e_{=}^{h}\right)+\left(1-b_{=}^{h^{\prime}}\right) R_{0}\left(e_{=}^{h}\right)-C\left(e_{=}^{h}\right) \\
& \leq b_{=}^{h^{\prime}} R_{1}\left(e_{=}^{h^{\prime}}\right)+\left(1-b_{=}^{h^{\prime}}\right) R_{0}\left(e_{=}^{h^{\prime}}\right)-\left(\frac{1}{\alpha} C\left(e_{=}^{h^{\prime}}\right)+\left(1-\frac{1}{\alpha}\right) C\left(e_{=}^{h}\right)\right) \\
& \leq b_{=}^{h^{\prime}} R_{1}\left(e_{=}^{h^{\prime}}\right)+\left(1-b_{=}^{h^{\prime}}\right) R_{0}\left(e_{=}^{h^{\prime}}\right)-C\left(e_{=}^{h^{\prime}}\right) .
\end{aligned}
$$

Proof of Proposition 4. For all $p>p^{S B}$ a realistic leader always chooses $x=s_{p}$ and expected surplus is equal to second best. Thus a realistic leader cannot do worse than a leader with overconfidence if $p>p^{S B}$. We show that there exists a $\bar{q}^{*}<1$ such that $p_{0} \geq p^{S B}$ for all $\bar{q} \geq \bar{q}^{*}$. For all such $\bar{q}$ the leader always chooses $x=s_{q}$ for some $p>p^{S B}$ which implies the result. $p_{0}$ is defined as the $p$ which solves

$$
\bar{q}(1-p)\left[R_{1}\left(e\left(b_{\neq}^{*}\right)\right)-R_{0}\left(e\left(b_{=}^{*}\right)\right)\right]=(1-\bar{q}) p\left[R_{1}\left(e\left(b_{=}^{*}\right)\right)-R_{0}\left(e\left(b_{\neq}^{*}\right)\right)\right] .
$$

We show that $\lim _{\bar{q} \rightarrow 1} p_{0}=1$. This then implies that there exists some $\bar{q} \equiv \bar{q}^{*}$ for which $p_{0}=p^{S B}$ and as $p_{0}$ is increasing in $\bar{q}$ the result follows. For $\bar{q} \rightarrow 1$ the right hand side of the above equation converges to zero. Under Condition (2) it holds that $\lim _{\bar{q} \rightarrow 1}\left[R_{1}\left(e\left(b_{\neq}^{*}\right)\right)-R_{0}\left(e\left(b_{=}^{*}\right)\right)\right]>0$ for all $p$. This implies that $\lim _{\bar{q} \rightarrow 1} p_{0}=1$.

Finally we show that (2) holds if $R$ and $C$ are twice continuously differentiable and $R^{\prime}(e, 0)-R^{\prime}(e, 1)$ and $C^{\prime \prime}(e)$ are nondecreasing. To see this note that for all $p$

$$
\begin{aligned}
\lim _{\bar{q} \rightarrow 1}\left[R_{1}\left(e\left(b_{\neq}^{*}\right)\right)-R_{0}\left(e\left(b_{=}^{*}\right)\right)\right] & =R_{1}(e(0))-R_{0}(e(1)) \\
& =\int_{0}^{e(0)} R_{1}^{\prime}(e) d e-\int_{0}^{e(1)} R_{0}^{\prime}(e) d e \\
& =\int_{0}^{e(0)} R_{1}^{\prime}(e)-R_{0}^{\prime}(e) d e-\int_{e(0)}^{e(1)} R_{0}^{\prime}(e) d e .
\end{aligned}
$$

The effort levels $e(0)$ and $e(1)$ are defined by $\alpha R_{0}^{\prime}(e(0))=C^{\prime}(e(0))$ and $\alpha R_{1}^{\prime}(e(1))=C^{\prime}(e(1))$, respectively. The fact that $C^{\prime \prime}$ is nondecreasing implies that 


$$
\begin{aligned}
\alpha R_{1}^{\prime}(e(1))-\alpha R_{0}^{\prime}(e(0)) & =C^{\prime}(e(1))-C^{\prime}(e(0)) \\
& =\int_{e(0)}^{e(1)} C^{\prime \prime}(e) d e \geq[e(1)-e(0)] C^{\prime \prime}(e(0)) .
\end{aligned}
$$

We therefore have

$$
\begin{aligned}
& \int_{e(0)}^{e(1)} R_{0}^{\prime}(e) d e<R_{0}^{\prime}(e(0))[e(1)-e(0)] \\
& \quad \leq \frac{C^{\prime}(e(0))}{C^{\prime \prime}(e(0))}\left[R_{1}^{\prime}(e(1))-R_{0}^{\prime}(e(0))\right] \\
& \leq e(0)\left[R_{1}^{\prime}(e(1))-R_{0}^{\prime}(e(0))\right]<e(0)\left[R_{1}^{\prime}(e(0))-R_{0}^{\prime}(e(0))\right] \\
& \quad \leq \int_{0}^{e(0)} R_{1}^{\prime}(e)-R_{0}^{\prime}(e) d e,
\end{aligned}
$$

where the last inequality follows as $R_{1}^{\prime}-R_{0}^{\prime}$ is nonincreasing.

Proof of Proposition 5. For all $p \leq p^{S B}$ the result immediately follows from Proposition 3 and the fact that $E[S]_{\bar{q}}^{N I}(p) \leq E[S]_{q}^{N I}(p)$ for all $p$ with strict inequality for $p \in(q, \bar{q})$. Thus suppose that $p>p^{S B}$. We have $E[S]_{q}^{I}(p)=E[S]_{q}^{N I}(p)$. It therefore remains to show that for all $\bar{q}>$ $q, E[S]_{\bar{q}}^{I}(p) \geq E[S]_{\bar{q}}^{N I}(p)$. If $p \geq \bar{q}$ then $E[S]_{\bar{q}}^{I}(p)=E[S]_{\bar{q}}^{N I}(p)$. If $p<\bar{q}$ then

$$
\begin{aligned}
E[S]_{\bar{q}}^{I}(p) & \geq E[S]^{S}(p) \\
& >q R_{1}(e(q))+(1-q) R_{0}(e(q))-C(e(q)) \\
& =E[S]_{\bar{q}}^{N I}(p) .
\end{aligned}
$$

The first inequality follows from the fact that using the hard evidence $x=s_{p}$ is second best and the self-confident leader might actually do so. Finally in the proof of Proposition 1 we have shown that $E[S]^{S}(p)$ is increasing and $\lim _{p \rightarrow \frac{1}{2}} E[S]^{S}(p)=q R_{1}(e(q))+(1-q) R_{0}(e(q))-C(e(q))$ which implies the last inequality.

Proof of Corollary 1. In text.

Proof of Proposition 6. Consider first the optimal $\alpha_{s}$ in the absence of information sharing. Note that $E\left[\Pi_{o}\right]^{N I}\left(\alpha_{s}\right)=E\left[R\left(e\left(\alpha_{s}\right)\right)\right]-E\left[C\left(e\left(\alpha_{s}\right)\right)\right]$, where $e\left(\alpha_{s}\right)=\arg \max \left(\alpha_{s} E[R(e)]-E[C(e)]\right)$. We have $\frac{\partial E\left[\Pi_{o}\right]^{N I}}{\partial \alpha_{s}}=\left(\frac{\partial E[R]}{\partial e}-\right.$ $\left.\frac{\partial E[C]}{\partial e}\right)\left(\frac{\partial e}{\partial \alpha_{s}}\right)$. The second part of this expression is positive for all $\alpha_{s}$, and the first part is positive whenever $\alpha_{s}<1$. Thus providing optimal incentives by letting $\alpha_{s} \rightarrow 1$ maximizes the owner's payoff. 
Under information sharing the problem is more complicated as the leader's decision depends on $\alpha_{s}$. To see this, consider the dependence of the leader's gain from following his own signal on $\alpha_{s}$ :

$$
\begin{aligned}
\frac{d G\left(b_{=}, b_{\neq}, \alpha_{s}\right)}{d \alpha_{s}}= & {\left[\frac{\partial R_{1}}{\partial e} \frac{\partial e\left(b_{\neq}\right)}{\partial \alpha_{s}}-\frac{\partial R_{0}}{\partial e} \frac{\partial e\left(b_{=}\right)}{\partial \alpha_{s}}\right] } \\
& +\frac{p(1-q)}{q(1-p)}\left[\frac{\partial R_{0}}{\partial e} \frac{\partial e\left(b_{\neq}\right)}{\partial \alpha_{s}}-\frac{\partial R_{1}}{\partial e} \frac{\partial e\left(b_{=}\right)}{\partial \alpha_{s}}\right] .
\end{aligned}
$$

When $\frac{\partial e\left(b_{=}\right)}{\partial \alpha_{s}} \leq \frac{\partial e\left(b_{\neq}\right)}{\partial \alpha_{s}}$ then (A41) is positive. Otherwise (A41) can be negative, in which case an increase in $\alpha_{s}$ leads to an increase in the leader's motivational bias. We complete the proof by showing with an example in which $\frac{\partial e\left(b_{=}\right)}{\partial \alpha_{s}}>\frac{\partial e\left(b_{\neq}\right)}{\partial \alpha_{s}}$ that the implied decrease in the quality of decision making can lower overall surplus and thus the owner's payoff.

We construct this example in the following way. First, we find revenue functions such that marginal revenue has a flat part and a steep part:

$$
\begin{aligned}
& R_{0} \equiv\left\{\begin{array}{cl}
0.3 e & \text { for } e \leq 0.3111 \\
0.0933+0.3(e-0.3111)-(e-0.3111)^{1.3} & \text { for } e \in(0.3111,0.313) \\
0.0936+0.1(e-0.313) & \text { for } e \geq 0.313
\end{array} \quad\right. \text { (A42) } \\
& R_{1} \equiv\left\{\begin{array}{cl}
0.5 e & \text { for } e \leq 0.3273 \\
0.1636+0.5(e-0.3273)-(e-0.3273)^{1.2} & \text { for } e \in(0.3273,0.3282) \\
0.1639+0.2(e-0.3282) & \text { for } e \geq 0.3282 .
\end{array}\right.
\end{aligned}
$$

Because effort is the solution to $\frac{\partial}{\partial e}\left[b R_{1}(e)+(1-b) R_{0}(e)\right]=\frac{1}{\alpha} \frac{\partial C}{\partial e}$, we can adjust the cost function and the values of $p$ and $q$ so that the subordinate's level of effort lies in the steep part when $\alpha$ is low and in the flat part when $\alpha$ is high. This implies that effort is very sensitive to the worker's belief for high values of $\alpha$ and very insensitive for low values. As a result, the leader distorts decision making for high $\alpha$, but not for low $\alpha$.

More specifically, let $q=0.6, p=0.5683$, and $C(e)=\frac{1}{2} e^{2}$ and consider expected surplus when $\alpha_{s} \rightarrow 1$. Note that we have chosen $p$ such that $e(p)=0.3273, e\left(b_{\neq}^{*}(p)\right)=0.313$ and $G\left(p, b_{\neq}^{*}(p)\right)=0$ for $\alpha_{s} \rightarrow$ 1 . This implies that for $\alpha_{s} \rightarrow 1$ the leader always chooses $x=s_{p}$ and the subordinate always exerts effort $e(p)=0.3273$. While effort is relatively large, decision making is poor because the leader has a strong incentive 
to distort his choice of project. The expected level of surplus and hence the owner's expected payoff is

$$
\lim _{\alpha_{s} \rightarrow 1} E\left[\Pi_{o}\right]^{I}=p R_{1}(0.3273)+(1-p) R_{0}(0.3273)-C(0.3273)=0.0804 .
$$

Consider now expected surplus when $\alpha_{s}=0.8563$. In this case $e\left(b_{=}^{*}(p)\right)=$ 0.313 and $e\left(b_{\neq}^{*}(p)\right)=0.311$. While effort is generally lower, it does not depend as strongly on the subordinate's belief. This implies that the leader has an incentive to choose $x=s_{q}$, which can be seen from the fact that $G\left(b_{=}^{*}(p), b_{\neq}^{*}(p)\right)=0.0017>0$. Decision making is of higher quality, and the owner's expected payoff is

$$
\begin{aligned}
E & {\left[\Pi_{o}\right]^{I}\left(\alpha_{s}=0.8563\right) } \\
= & \operatorname{Pr}\left(s_{q}=s_{p}\right)\left(b_{=}^{*} R_{1}(0.313)+\left(1-b_{=}^{*}\right) R_{0}(0.313)-C(0.313)\right) \\
& +\operatorname{Pr}\left(s_{q} \neq s_{p}\right)\left(b_{\neq}^{*} R_{1}(0.3112)+\left(1-b_{\neq}^{*}\right) R_{0}(0.3112)-C(0.3112)\right) \\
= & 0.0823 .
\end{aligned}
$$

A decrease in $\alpha_{s}$ from 1 to 0.8563 increases the owner's expected profit.

\section{REFERENCES}

Aghion, P. and J. Tirole, 1997, "Formal and Real Authority in Organisations," Journal of Political Economy, 105, 1-29.

Alkhafaji, A.F., 1997, Strategic Management: Formulation, Implementation and Control in a Dynamic Environment, New York: Haworth Press.

Alpert, M. and H. Raiffa, 1982, "A Progress Report on the Training of Probability Assessors," in D. Kahneman, P. Slovic, and A. Tversky, eds., Judgment Under Uncertainty: Heuristics and Biases, Cambridge, UK: Cambridge University Press.

Aumann, R.J., 1976, "Agreeing to Disagree," The Annals of Statistics, 4, 1236-1239.

Barber, B. and T. Odean, 2001, "Boys Will Be Boys: Gender, Overinvestment and Common Stock Investment," Quarterly Journal of Economics, 116, 261-292.

Bar-Gill, O., 2002, “The Evolution and Persistence of Optimism in Litigation," Discussion Paper 375, John M. Olin Center for Law, Economics and Business, Harvard Law School.

Bernardo, A. and I. Welch, 2001, "On the Evolution of Overconfidence and Entrepreneurs," Journal of Management, Economics and Strategy, 10, 301-330.

Branderburger, A. and B. Polak, 1996, "When Managers Cover their Posteriors: Making the Decisions the Market Wants to See," RAND Journal of Economics, 27, 527-541.

Camerer, C. and D. Lovallo, 1999, "Overconfidence and Excess Entry: An Experimental Approach," American Economic Review, 89, 306-318.

DeLong, J., A. Shleifer, L. Summers, and R. Waldmann, 1990, "The Survival of Noise Traders in Financial Markets," Journal of Business, 64, 1-20.

Fischhoff, B., P. Slovic, and S. Lichtenstein, 1977, “Knowing with Certainty: The Appropriateness of Extreme Confidence," Journal of Experimental Psychology, 3, 552-564.

Gervais, S. and T. Odean, 2001, "Learning to Be Overconfident," Review of Financial Studies, 14, 1-27. 
— and I. Goldstein, 2005, “Overconfidence and Team Coordination," Mimeo.

Hermalin, B., 1998, "Toward an Economic Theory of Leadership: Leading by Example," American Economic Review, 88, 1188-1206.

Holmstrom, B., 1982, "Moral Hazard in Teams," Bell Journal of Economics, 13, 324-340.

Hume, D.A., 1740, Treatise of Human Nature, Oxford, UK: Oxford University Press.

Kets de Vries, M., 2003, Leaders, Fools and Impostors: Essays on the Psychology of Leadership, iUniverse.com.

Kyle, A. and F. Wang, 1997, “Speculation Duopoly with Agreement to Disagree: Can Overconfidence Survive the Market Test?," Journal of Finance, 52, 2073-2090.

Laffont, J.J. and D. Martimort, 2001, The Theory of Incentives, Princeton, NJ: Princeton University Press.

Landier, A., D. Sraer, and D. Thesmar, 2006, “Optimal Dissent in Organizations," Mimeo.

Li, H., S. Rosen, and W. Suen, 2001, "Conflicts and Common Interests in Committees," American Economics Review, 91, 1478-1497.

Lundeberg, M., P. Fox, and J. Puncchohar, 1994, "Highly Confident but Wrong: Gender Differences and Similarities in Confidence Judgments," Journal of Educational Psychology, 86, 114-121.

Malmendier, U. and G. Tate, 2005a, "CEO Overconfidence and Corporate Investment," Journal of Finance, 60, 2661-2700.

$\longrightarrow$, and $\_$, 2005b, "Who Makes Acquisitions? CEO Overconfidence and Market Reaction," Mimeo.

Milgrom, P. and C. Shannon, 1994, "Monotone Comparative Statics," Econometrica, 62, 157- 180.

Morris, S., G. Willkers, and E. Knasel, 1999, How to Lead a Winning Team, New York: Prentice Hall.

Northouse, P.G., 2004, Leadership: Theory and Practise, Thousand Oaks, CA: Sage.

Prendergast, C., 1993, “A Theory of Yes-Men," American Economic Review, 83, 757-770.

Rotemberg, J. and G. Saloner, 1994, “Leadership Style and Incentives," Management Science, $39,1299-1318$.

— Economics, 31, 693-717.

Van den Steen, E., 2001, “Essays on the Managerial Implications of Differing Priors," PhD Dissertation, Stanford University.

__ 2004, "Rational Overoptimism (and Other Biases)," American Economic Review, 94, $1141-1151$.

_, 2005 , "Organisational Beliefs and Managerial Vision," Journal of Law, Economics, and Organisation, 21, 256-283.

Yukl, G., 2005, Leadership in Organisations, New York: Prentice Hall.

Zabojnik, J., 2002, "Centralized and Decentralized Decision-Making in Organisations," Journal of Labor Economics, 20, 1-22.

_ 2004, "A Model of Rational Bias in Self-Assessments," Economic Theory, 23, 259-282. 
